Supplement of Atmos. Chem. Phys., 20, 7049-7068, 2020

https://doi.org/10.5194/acp-20-7049-2020-supplement

(C) Author(s) 2020. This work is distributed under

the Creative Commons Attribution 4.0 License.

(c) (i)

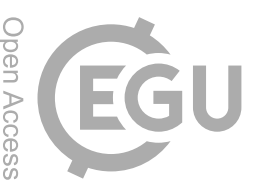

Supplement of

\title{
Decreasing trends of particle number and black carbon mass concentrations at 16 observational sites in Germany from 2009 to 2018
}

\section{Jia Sun et al.}

Correspondence to: Nan Ma (nan.ma@jnu.edu.cn) and Alfred Wiedensohler (alfred.wiedensohler@tropos.de)

The copyright of individual parts of the supplement might differ from the CC BY 4.0 License. 


\section{Robustness of the trends}

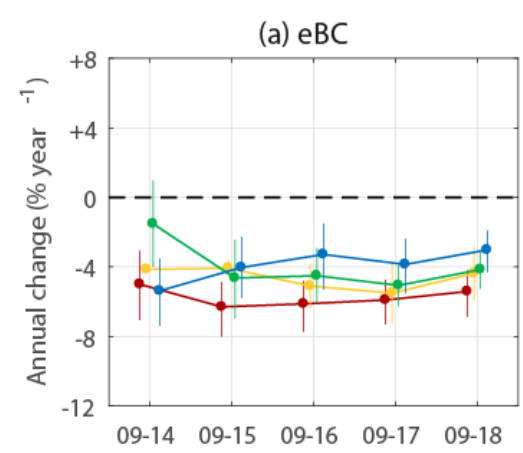

(d) $\mathrm{N}$

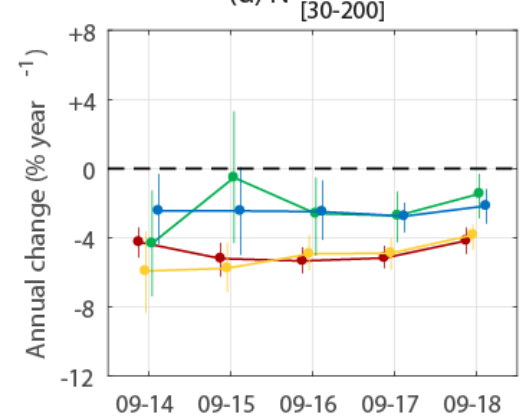

(b) $\mathrm{N}$

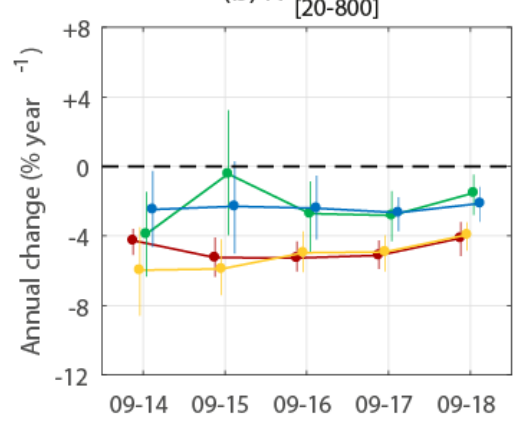

(e) $\mathrm{N}$

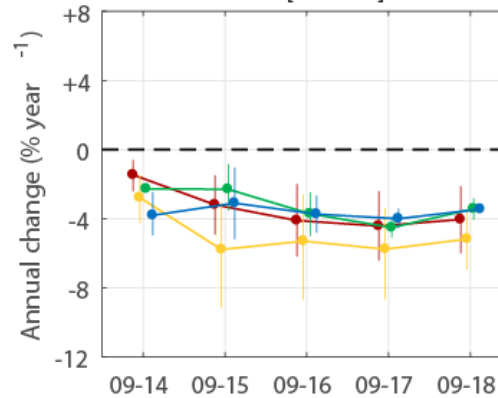

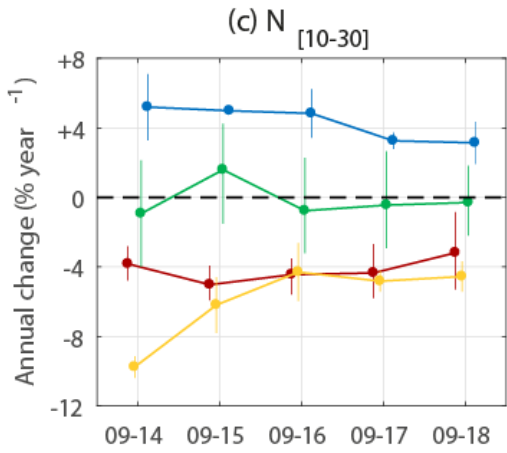

- RS
UB
RB
LMT \& HA

Figure S1: Annual trends of PNCs and eBC mass concentration for expanding time intervals starting from 2009, using the customized Sen's estimator. The x-axis shows the starting and ending year. The dots denote the mean slope and the whiskers denote the $75^{\text {th }}$ and $25^{\text {th }}$ percentiles. The trend evolution for each site category is illustrated: roadside (RS), urban background (UB), regional background (RB), low mountain range and high Alpine (LMT\&HA).

For the time series of a climate parameter, the determination of its long-term trend might be sometimes influenced by inhomogeneous "break points" such as site relocation, inlet change, and new pollution sources (Collaud Coen et al., 2013). The break points not only make the time series inhomogeneous but also result in a poor representativeness of the trend. Normally, only the trends of homogeneous time series are considered to be robust and trustable. Another important factor affecting the trend is the length of the time series. To evaluate if the time span of our dataset is long enough to provide a robust trend, the evolution of trend was analyzed. Fig. S1 shows the Sen's slopes (annual relative changes) of the PNCs and eBC mass concentration for expanding time intervals starting from 2009. The average slopes for each site category are illustrated. It can be seen that the trends tend to be stable without strong variation after time interval 2009-2016, indicating the time span of our observation is long enough for the detection of trustable longterm trends.

Gaps in time series may also bias the observed trends. Generally, it is difficult to quantify clearly the influence of data gaps on the trend results. In this study, since the influences of periodicity and outliers are 
diminished by applying customized Sen's estimator, the evaluated trends are less sensitive to data gaps than those derived by other methods.

Table S1: Number of sites used in trend analysis.

\begin{tabular}{ccc}
\hline Parameters & Number of stations analysed & Excluded stations \\
\hline $\mathrm{eBC}$ & 14 & MST, LAN \\
$N_{[20-800]}$ & 16 & -- \\
$N_{[10-30]}$ & 14 & MST, ZSF \\
$N_{[30-200]}$ & 16 & -- \\
$N_{[200-800]}$ & 16 & -- \\
\hline
\end{tabular}

\section{Emission change on sectors}

(a) $\mathrm{BC}$

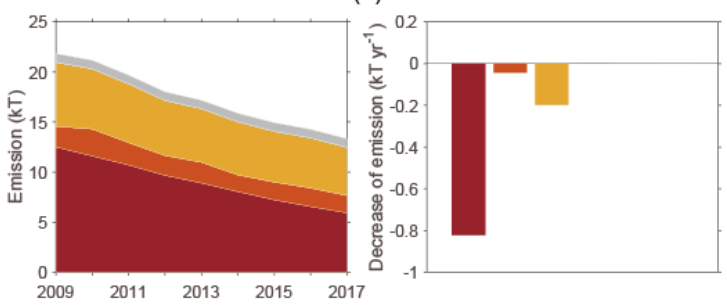

(c) $\mathrm{SO}_{2}$
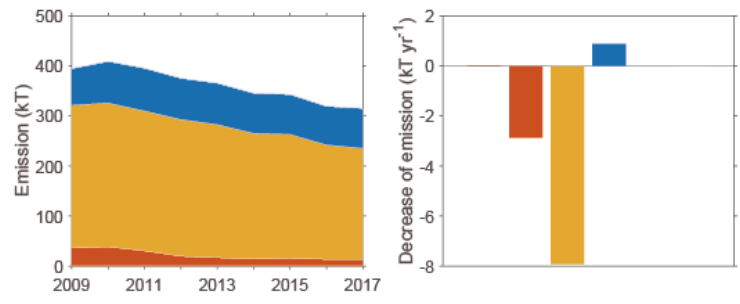

(e) $\mathrm{NH}_{3}$
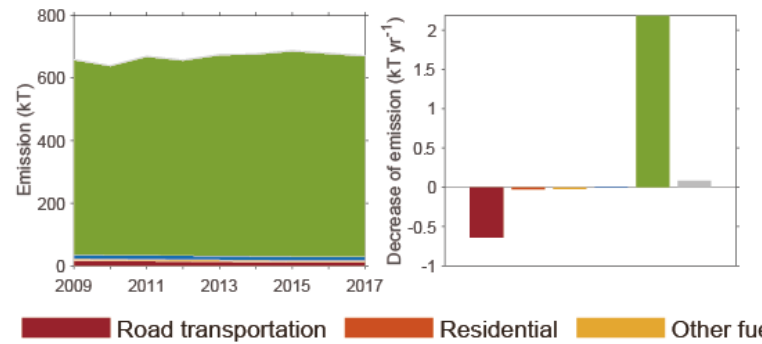

(b) $\mathrm{PM}_{2.5}$

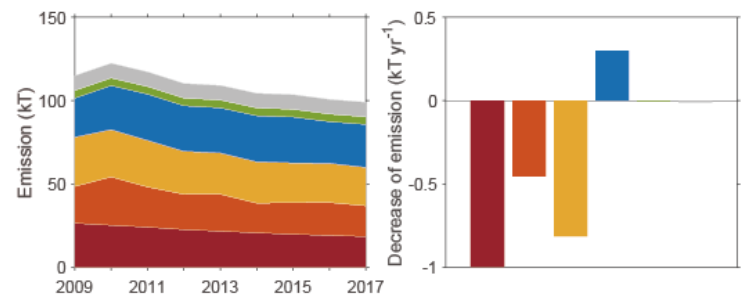

(d) $\mathrm{NO}_{x}$

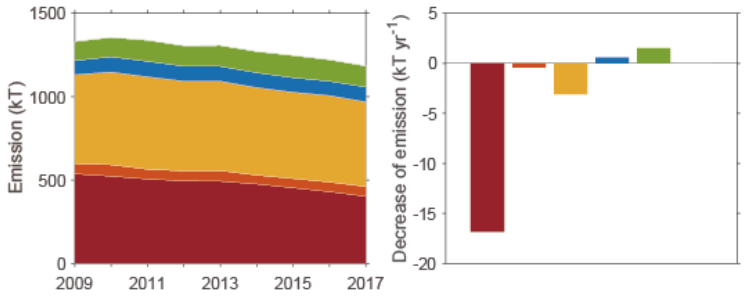

(f) NMVOC

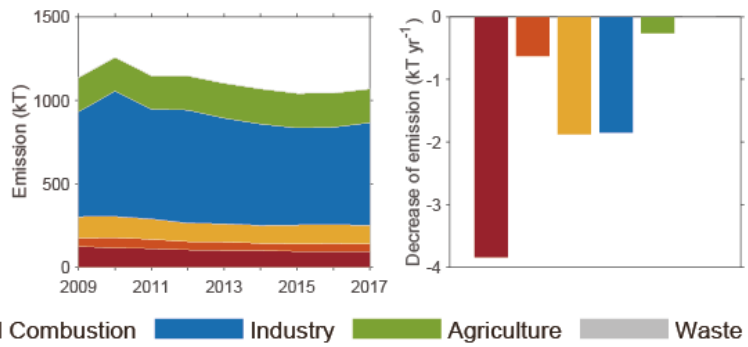

Figure S2: The long-term changes of total emissions of BC, $\mathrm{PM}_{2.5}$ and precursors on sectors during 2009-2017 in Germany (UBA, 2020). For each species, the left panel gives the total absolute emissions in different sectors; and the right panel shows their trends. 


\section{Back trajectory cluster method (BCLM)}

Air mass classification is a powerful tool to assess the influence of meteorological conditions on long-term atmospheric observations. In this work, air masses were classified on a daily basis for the period 2009-2018 using a Back Trajectory and Temperature Profile (BTTP) cluster method.

\section{Basic description}

The Back Trajectory and Temperature Profile (BTTP) cluster method classifies air masses based on their meteorological back trajectories in combination with experimental radiosoundings recorded during the same period. The meteorological back trajectories provide information on the spatial origin and pathways of air pollutants measured at a receptor site, while the radiosounding profiles characterize the vertical stability of atmosphere and the effect of dilution of pollutants emitted near the surface (Stull, 2012). The BTTP cluster algorithm is a variant of algorithm versions previously used for the analysis of atmospheric particle number size distributions (Birmili et al., 2010; Engler et al., 2007; Engler et al., 2012; Heintzenberg et al., 2011) and aerosol scattering coefficients (Ma et al., 2014). In contrast to the previous versions, the current BTTP method is extended to represent the whole Germany as a receptor area, encompassing a total of nine sites for numerical back trajectories and seven sites for experimental radiosoundings. The use of multiple sites makes the air mass classification scheme representative not just for a single observation site but for the entire German ultrafine aerosol network (GUAN).

\section{Data resources}

For the BTTP cluster algorithm, 3D-backward trajectories were calculated for 2009-2018 using a PC version of HYSPLIT, a trajectory model provided by the National Oceanic and Atmospheric Administration (NOAA) Air Resources Laboratory (Stein et al., 2015). Back trajectories were computed based on the Global Data Assimilation System (GDAS) analysis set which provides meteorological fields every $3 \mathrm{~h}$, at a horizontal resolution of $1^{\circ}$, and at numerous standard pressure levels. 96-hour backward trajectories reaching at the receptor site were computed daily for a starting time of 12:00 UTC and a starting altitude of $500 \mathrm{~m}$ above ground for the nine following locations: Augsburg (latitude: $48.36^{\circ} \mathrm{N}$, latitude: $10.91^{\circ} \mathrm{E}$ ), Bösel $\left(53.00^{\circ} \mathrm{N}, 7.96^{\circ} \mathrm{E}\right)$, Fulda $\left(50.55^{\circ} \mathrm{N}, 9.68^{\circ} \mathrm{E}\right)$, Melpitz $\left(51.54^{\circ} \mathrm{N}, 12.93^{\circ} \mathrm{E}\right)$, Mülheim $\left(51.45^{\circ} \mathrm{N}\right.$, $\left.6.87^{\circ} \mathrm{E}\right)$, Schauinsland $\left(47.91^{\circ} \mathrm{N}, 7.91^{\circ} \mathrm{E}\right)$, Waldhof $\left(52.80^{\circ} \mathrm{N}, 10.76^{\circ} \mathrm{E}\right)$, Zingst $\left(54.44^{\circ} \mathrm{N}, 12.68^{\circ} \mathrm{E}\right)$, and Zugspitze $\left(47.42^{\circ} \mathrm{N}, 10.98^{\circ} \mathrm{E}\right)$. Seven of these sites coincide with GUAN sites, two additional locations (Fulda, Zingst) were introduced to cover the area of Germany (roughly $1000 \times 700 \mathrm{~km}$ ) more evenly.

Vertical profiles of pseudopotential temperature $\theta_{v}$ were retrieved from radiosounding data provided in the Upper Air section of the University of Wyoming Weather Web (University of Wyoming, Department of Atmospheric Science, Laramie, WY, USA). As in the case of the back trajectories, we strived to cover the area of Germany comprehensively. Radiosounding data from the following sites at 12:00 UTC were used: Bergen (WMO station code 10238, latitude: 52.81 ${ }^{\circ} \mathrm{N}$, longitude: $9.93{ }^{\circ} \mathrm{E}$, altitude: $69 \mathrm{~m}$ ), Essen 
(WMO 10410, 51.40 $\mathrm{N}, 6.97^{\circ} \mathrm{E}, 147 \mathrm{~m}$ ), Lindenberg (WMO 10393, 52.21 ${ }^{\circ} \mathrm{N}, 14.12^{\circ} \mathrm{E}, 112 \mathrm{~m}$ ), Meiningen (WMO 10548, 50.56 $\mathrm{N}, 10.38^{\circ} \mathrm{E}, 450 \mathrm{~m}$ ), München-Oberschleissheim (WMO 10868, 48.25 $\mathrm{N}, 11.55^{\circ} \mathrm{E}, 492 \mathrm{~m}$ ), Schleswig (WMO 10035, 54.53 ${ }^{\circ} \mathrm{N}, 9.55^{\circ} \mathrm{E}, 47 \mathrm{~m}$ ), and Stuttgart (WMO 10739, 48.83 $\left.\mathrm{N}, 9.20^{\circ} \mathrm{E}, 321 \mathrm{~m}\right)$. These profiles of $\theta_{v}$ characterise the vertical structure of the atmosphere daily around mid-day. To represent the boundary layer, profile information was used between ground level and a height of $3300 \mathrm{~m}$ above ground. Importantly, it is not the absolute value of $\theta_{v}$ that matters for the likelihood of vertical air exchange but its vertical gradient (Stull, 2012). To make the profiles comparable throughout all seasons, all profiles were normalized to $0^{\circ} \mathrm{C}$ at a fixed height above ground. To avoid interference with surface-related phenomena such as local overheating, this height was set to $300 \mathrm{~m}$ above ground level at each site. Radiosounding profiles were re-gridded in order to match the length of the back trajectory vectors.

\section{Cluster algorithm}

Our cluster algorithm follows the $k$-means approach for clustering meteorological back trajectories (Dorling et al., 1992). In $k$-means clustering a fixed number $k$ of clusters is defined prior to analysis. The algorithm aims at minimizing the distances between each object (3D-trajectory, and $\theta_{v}$ profile) to its cluster mean while maximizing the distances among different cluster means. In other words, trajectories are to be clustered in bundles as narrow as possible, with the difference among bundles being as large as possible. As a measure for the distance $D$ between two objects, the following expression was used.

$$
D=\sum_{i}\left[l_{i} *\left(\left(\omega_{\beta} * \Delta \beta_{i}\right)^{2}+\left(\omega_{z} * \Delta z_{i}\right)^{2}+\left(\omega_{\theta} * \Delta \theta_{i}\right)^{2}\right)\right]
$$

where, $\omega_{\beta}$ is the distance between two trajectory points in degrees in spherical coordinates. $\omega_{z}$ is the distance between trajectories in the vertical dimension (height $z$ ). And $\omega_{\theta}$ is the difference between two corresponding points in the vertical profiles of $\theta_{v}$. All squared distances are summed over the entire length of the trajectory vector (index $i$ ), weighted with a distance factor $l_{i}$. The distance factor $l_{i}$ was set to unity at the start of the trajectory, and 0.2 at the end of each 96 h-trajectory, linearly interpolating in between. For the $\theta_{v}$ profiles, this corresponds to a weighing factor of 1 near the surface, and 0.2 aloft. The distance factor ensures that distances between trajectories and $\theta_{v}$ profiles far from the receptor point are not overemphasized. To make horizontal and vertical trajectory distances as well as distances in $\theta_{v}$ comparable both in magnitude and units, each parameter was scaled by appropriate weights.

For the first step, the $k$-means cluster algorithm assigns all trajectories to $k$ pre-defined clusters based on the minimum distance $D$ between the trajectories and $\theta_{v}$ profiles. The pre-defined clusters involve straight trajectories radiating from the nine sites listed above in different directions, thereby sharing equal segments of the $360^{\circ}$ horizon. Once all objects are allocated to their appropriate seed trajectory by the principle of the minimum distance $D$, new cluster mean values are calculated from all objects (3D-trajectory, and $\theta_{v}$ profile) within each cluster. Then, a new iteration is started, re-allocating all objects to the nearest 
new cluster means. This procedure is repeated until the allocation of objects to the $k$ clusters converges and no more re-allocation occurs.

It is an intrinsic property of the $k$-means clustering method that different initializations of the $k$ seed trajectories might yield different clustering results. Likewise, the use of different weighing factors will usually yield different clustering results. Therefore, the cluster algorithm was run many times, using a range of cluster numbers $k$, and different angles of the $k$ seed trajectories. Also, a range of weights $\omega_{\beta}, \omega_{z}$ and $\omega_{\theta}$ was used to check the sensitivity of the clustering results with respect to variations in these weights. In total, several 100 cluster analyses were performed, most of which yielded different cluster compositions.

\section{Evaluation of cluster results}

From previous work (Engler et al., 2012) we learned that in Central Europe surface-measured $\mathrm{PM}_{10}$ is a parameter rather sensitive towards the occurrence of different air mass types and seasonal variations in meteorology. We therefore evaluated the performance of the cluster algorithm with the aid of $\mathrm{PM}_{10}$ mass concentration data, a pollution parameter that is widely available from government monitoring sites in Germany (Minkos et al., 2019). For the evaluation, we collected $\mathrm{PM}_{10}$ mass concentrations from a total of 142 urban and rural background stations across Germany.

As a numerical criterion for the algorithm's performance we computed a spread parameter $S$ representing the standard deviation of the $\mathrm{PM}_{10}$ mean values for the $\mathrm{k}$ clusters from a particular cluster analysis run, weighted with the number of trajectories contained in each cluster. If this spread parameter $S$ is high, a particular run is considered capable to explain the variations in $\mathrm{PM}_{10}$ as a function of back trajectories and $\theta_{v}$ profiles. If $S$ is low, the particular run is obviously inefficient in explaining variations in $\mathrm{PM}_{10}$ mass concentrations. Guided by experience (Engler et al., 2012), we tested the cluster algorithm for a range of cluster numbers between 8 and 19. Our preferred solution contains a cluster number of $k=15$. The judgement is based on observing more and more redundancies in the cluster composition (i.e. cluster means close to each other) for $k>15$. Reducing the number of clusters below 15 would, conversely, merge clusters that could be clearly identified as typical weather situations in Central Europe. With respect to the weights $\omega_{\beta}, \omega_{z}$ and $\omega_{\theta}$, we checked the following range of settings: $\omega_{\beta}=1{ }^{\circ}$ (default), $\omega_{z}=0 \sim 1 \mathrm{~m}^{-1}, \omega_{\theta}=0 \sim 10 \mathrm{~K}^{-1}$. Sensitivity analysis revealed that the geographical origin of trajectories $(\beta)$ and vertical stratification $\left(\theta_{v}\right.$ profile) mattered most to achieve a good cluster separation. The vertical trajectory coordinate $z$ turned out to be irrelevant to explaining variations in $\mathrm{PM}_{10}$ mass concentrations so it was subsequently set $\omega_{z}=0$ and ignored hereafter.

\section{Final cluster solution}

The final cluster solution was obtained with a number of $k=15$ clusters (i.e. air masses) and the settings $\omega_{\beta}=1{ }^{\circ}$ (default), $\omega_{z}=0$, and $\omega_{\theta}=1.6 \mathrm{~K}^{-1}$. The particular individual solution was selected among a group of 5 almost equivalent solutions having the largest separation parameter $S$, and providing a good visual 
display of back trajectory cluster means. The 15 cluster means (i.e. air masses) were labelled according to a system distinguishing seasonality and vorticity of the atmospheric circulation over central Europe. The 15 clusters are named by seasons (CS: cold season, clusters composed predominantly of days centred around 15 January in winter; WS: warm season, those centred around 15 July; TS: transition season, those with most cases in between) and synoptic patterns (ST: Stagnant flow with no clear preference; A1: Anticyclonic with air mass originating from Eastern Europe; A2: Anti-cyclonic with air mass originating from west; $\mathrm{C} 1$ : cyclonic with air mass originating from relatively south; $\mathrm{C} 2$ : cyclonic with air mass originating from the north). This nomenclature was chosen because it is familiar to meteorologists and can be linked to the existing knowledge of climatology in Central Europe. The solution presented here is, according to our judgement, an optimum representation of air masses in Central Europe with the aim of describing contrasts in surface-measured PM parameters.

\section{Reference}

Birmili, W., Heinke, K., Pitz, M., Matschullat, J., Wiedensohler, A., Cyrys, J., Wichmann, H. E., and Peters, A.: Particle number size distributions in urban air before and after volatilisation, Atmos. Chem. Phys., 10, 4643-4660, 10.5194/acp-10-4643-2010, 2010.

Collaud Coen, M., Andrews, E., Asmi, A., Baltensperger, U., Bukowiecki, N., Day, D., Fiebig, M., Fjaeraa, A. M., Flentje, H., Hyvarinen, A., Jefferson, A., Jennings, S. G., Kouvarakis, G., Lihavainen, H., Myhre, C. L., Malm, W. C., Mihapopoulos, N., Molenar, J. V., O'Dowd, C., Ogren, J. A., Schichtel, B. A., Sheridan, P., Virkkula, A., Weingartner, E., Weller, R., and Laj, P.: Aerosol decadal trends Part 1: In-situ optical measurements at GAW and IMPROVE stations, Atmos. Chem. Phys., 13, 869894, 10.5194/acp-13-869-2013, 2013.

Dorling, S. R., Davies, T. D., and Pierce, C. E.: Cluster analysis: A technique for estimating the synoptic meteorological controls on air and precipitation chemistry-Method and applications, Atmos. Environ., 26, 2575, 1992.

Engler, C., Rose, D., Wehner, B., Wiedensohler, A., Brüggemann, E., Gnauk, T., Spindler, G., Tuch, T., and Birmili, W.: Size distributions of non-volatile particle residuals $\left(\mathrm{D}_{\mathrm{p}}<800 \mathrm{~nm}\right)$ at a rural site in Germany and relation to Airmass origin, Atmos. Chem. Phys., 7, 5785-5802, 10.5194/acp-7-57852007, 2007.

Engler, C., Birmili, W., Spindler, G., and Wiedensohler, A.: Analysis of exceedances in the daily PM $_{10}$ mass concentration $\left(50 \mu \mathrm{g} \mathrm{m}^{-3}\right)$ at a roadside station in Leipzig, Germany, Atmos. Chem. Phys., 12, 10107-10123, 10.5194/acp-12-10107-2012, 2012. 
Heintzenberg, J., Birmili, W., Otto, R., Andreae, M. O., Mayer, J.-C., Chi, X., and Panov, A.: Aerosol particle number size distributions and particulate light absorption at the ZOTTO tall tower (Siberia), 2006-2009, Atmospheric Chemistry \& Physics Discussions, 11, 1153, 2011.

Ma, N., Birmili, W., Müller, T., Tuch, T., Cheng, Y. F., Xu, W. Y., Zhao, C. S., and Wiedensohler, A.: Tropospheric aerosol scattering and absorption over central Europe: a closure study for the dry particle state, Atmos. Chem. Phys., 14, 6241-6259, 10.5194/acp-14-6241-2014, 2014.

Minkos, A., Dauert, U., Feigenspan, S., and Kessinger, S.: Air Quality 2018 - Preliminary Evaluation, Federal Environment Agency (Umweltbundesamt), Dessau-Rosslau, Germany, 28, 2019.

Stein, A. F., Draxler, R. R., Rolph, G. D., Stunder, B. J. B., Cohen, M. D., and Ngan, F.: NOAA's HYSPLIT Atmospheric Transport and Dispersion Modeling System, Bulletin of the American Meteorological Society, 96, 2059-2077, 10.1175/bams-d-14-00110.1, 2015.

Stull, B. R.: An introduction to boundary layer meteorology, Springer Science \& Business Media, 2012.

UBA (German Federal Environmental Agency): German Informative Inventory Report 2020 (IIR 2020). available at http://iir-de.wikidot.com/ and https://www.umweltbundesamt.de/themen/luft/emissionenvon-luftschadstoffen; access: 15 December 2019. 